\title{
A Circumscribed Projection from the Nucleus of the Solitary Tract to the Nucleus Ambiguus in the Rat: Anatomical Evidence for Somatostatin-28-Immunoreactive Interneurons Subserving Reflex Control of Esophageal Motility
}

\author{
E. T. Cunningham, Jr. ${ }^{1,2, a}$ and P. E. Sawchenko ${ }^{2}$ \\ 'Department of Neurosciences, University of California, San Diego, La Jolla, California 92093, and ${ }^{2}$ The Salk Institute for \\ Biological Studies and The Clayton Foundation for Research-California Division, La Jolla, California 92037
}

\begin{abstract}
Axonal transport and immunohistochemical methods were used to investigate the anatomical and biochemical organization of projections from the nucleus of the solitary tract (NTS) to the rostral, esophageal, part of the nucleus ambiguus (NA) in the rat. Discrete iontophoretic deposits of a retrogradely transported tracer, fluorogold, placed in the rostral NA labeled a column of cells within the NTS, termed the central part of the NTS (after Ross et al., 1985), situated just medial to the solitary tract and extending from about 300 to $1000 \mu \mathrm{m}$ rostral to the obex. Iontophoretic deposits of the anterogradely transported tracer, Phaseolus vulgaris-leucoagglutinin (PHA-L), placed in the central part of the NTS gave rise to dense and topographically restricted projections to the rostral NA. More caudal and ventral aspects of the NA did not receive prominent inputs from the central part of the NTS, and deposits that spared the central part of the NTS gave rise to only sparse projections to the rostral NA. Antisera against somatostatin-28 (SS-28) stained cell bodies within the central part of the NTS. In addition, a doublelabeling procedure, capable of colocalizing anterogradely transported PHA-L and endogenous peptides to individual fibers and/or terminals, demonstrated an appreciable number of SS-28-immunoreactive terminals within the rostral NA that arose from the NTS. Correspondingly, unilateral lesions that involved the central part of the NTS resulted in a marked depletion of SS-28 immunoreactivity in the ipsilateral rostral NA. These data provide evidence for a discrete, partly somatostatinergic, projection from the central part of the NTS to the rostral NA. Anatomical and physiological studies implicating the central part of the NTS and the rostral NA in esophageal function suggest this pathway to be involved in the reflex control of esophageal motility.
\end{abstract}

\footnotetext{
Received Aug. 22, 1988; revised Oct. 17, 1988; accepted Oct. 18, 1988

Supported by NIH Grant HL-35137, a McKnight Foundation Scholar's award (P.E.S.) and by a Grant-in-Aid of Research from Sigma Xi (E.T.C., Jr.). This work was conducted in part by the Clayton Foundation for Research-California Division; P.E.S. is a Clayton Foundation Investigator. We thank R. Benoit for generously providing antisera to somatostatin, and R. Benoit and L. W. Swanson for having thoughtfully read and commented on the manuscript. We also thank Carrie Norita, Daniel Aklufi, and Carlos Arias (technical), Kris Trulock (photographic), and Belle Wamsley (secretarial) for excellent assistance.

Correspondence should be addressed to P. E. Sawchenko, The Salk Institute, P.O. Box 85800, San Diego, CA 92138.

a Present address: The Johns Hopkins University, School of Medicine, Baltimore, MD 21205 .

Copyright (c) 1989 Society for Neuroscience $0270-6474 / 89 / 051668-15 \$ 02.00 / 0$
}

The nucleus of the solitary tract (NTS) occupies a pivotal position in the central visceromotor system. Projections of the Vth, VIIth, IXth, and Xth cranial nerves terminate centrally within the NTS, conveying sensory information from the oral, thoracic, and abdominal cavities. The NTS, in turn, projects to virtually all levels of the neuraxis, so as to coordinate appropriate bchavioral, neuroendocrine, and autonomic responses (see Sawchenko, 1983; Norgren, 1984, for reviews).

Prominent among the projections of the NTS is an input to the ventrolateral medulla (Morest, 1967; Cottle and Calaresu, 1975; Palkovits and Záborszky, 1977; Loewy and Burton, 1978; Norgren, 1978; Ricardo and Koh, 1978; Beckstead et al., 1980; Sawchenko and Swanson, 1982; Bieger, 1984; Stuesse and Fish, 1984; Ross et al., 1985; Lovick, 1986; Dampney et al., 1987; Blessing et al., 1987), a region whose best-characterized output neurons include catecholaminergic neurons of the $\mathrm{Al}$ and $\mathrm{Cl}$ cell groups and motor neurons of the vagus and glossopharyngeal nerves. Current evidence suggests that the catecholaminergic cell groups play distinctive roles in autonomic and/ or neuroendocrine controls of stress- and cardiovascular-related responses (Ross et al., 1981, 1983, 1984; Sawchenko and Swanson, 1982; Cunningham and Sawchenko, 1987, 1988; Morrison et al., 1988; see Ciriello et al., 1986, and Rcis, 1988, for reviews). By contrast, the function of vagal and glossopharyngeal motor neurons in the ventrolateral medulla has remained a topic of debate, due primarily to conflicting data concerning the representation of the various viscera in the ambigual complex (see Bieger and Hopkins, 1987, for review). The selectivity, in terms of the distribution, cells of origin, and chemical coding, of NTS projections to each of these individual cell groups has not yet been deciphered. The present study represents an initial attempt to evaluate the specificity of projections from the NTS to the ventrolateral medulla, focusing first on inputs to the nucleus ambiguus (NA).

Recently, Bieger and Hopkins (1987) employed retrograde tracing techniques to address the issue of viscerotopy within the nucleus ambiguus (NA). Their results, in agreement with many of the degeneration studies done at the turn of the century (see Molhant, 1914, and Lawn, 1966, for reviews), provide strong evidence for apportioning the NA into 4 subdivisions based on cell size, packing density, and peripheral targets. Three of these subdivisions, or formations as they have been termed, comprise the NA of the more classical descriptions, known for some time to innervate branchiomeric derivatives in the head and neck. From rostral to caudal these subdivisions are the esophageal, 
or compact, formation (cf); the palatopharyngeal, or scmicompact, formation (scf); and the laryngeal, or loose, formation (If). The fourth subdivision, composed of scattered cells lying ventral to the branchiomeric subdivisions, was termed the external formation (ef) and has been shown to innervate the heart (see Bieger and Hopkins, 1987; Hopkins, 1987).

Projections from the NTS to the NA have been suggested by numerous investigators. Retrograde transport studies have described all aspects of the caudal NTS as projecting to the ventrolateral medulla (Bieger, 1984; Stuesse and Fish, 1984; Ross et al., 1985; Lovick, 1986; Blessing et al., 1987; Dampney, 1987), and anterograde tracing studies employing the autoradiographic method have described relatively diffuse projections from the medial part of the NTS to this region (Loewy and Burton, 1978; Norgren, 1978; Ricardo and Koh, 1978; Beckstead et al., 1980; Sawchenko and Swanson, 1982; Ross et al., 1985). Interestingly, only those cases in which tracer deposits involved the region of the rostral aspect of the NA displayed labeling of a relatively circumscribed cluster of neurons in the medial part of the NTS (Bieger, 1984; Stuesse and Fish, 1984; Ross et al., 1985), a cell group termed the central part of the NTS by Ross and colleagues (1985). This region has been implicated both anatomically (Fryscak et al., 1984; Altschuler et al., 1988) and physiologically (Jean, 1972a, b, 1978; Amri et al., 1984; Bieger, 1984) as receiving esophageal sensory information (see Jean, 1984; Miller, 1986,1987 , for reviews).

The purpose of the present study was to investigate the precise topography and transmitter specificity of the projection from the central part of the NTS to the ambigual complex. The results provide support for the existence of an anatomically and biochemically defined group of NTS interneurons subserving reflex control of esophageal motility.

\section{Materials and Methods}

Adult albino rats of the Sprague-Dawley strain were used in all experiments. All surgery was carried out under chloral hydrate anesthesia $(350 \mathrm{mg} / \mathrm{kg}$, i.p.), using a direct approach to the caudal medulla after reflection of the atlanto-occipital membrane. Empirically determined stereotaxic coordinates were used for tracer and lesion placement.

Retrograde tracing experiments. Iontophoretic deposits of a $2.0 \%$ solution of the retrogradely transported fluorescent dye, fluorogold $(\mathrm{FG}$, Fluorochrome, Inc.; Schmued and Fallon, 1986) in $0.15 \mathrm{M} \mathrm{NaCl}$ were made into the region of the rostral NA. Deposits were made over 10 min through $10 \mu \mathrm{m}$ (i.d.) glass micropipettes, using a constant-current device (Model CS-3; Transkinetics, Inc.) set to deliver $+2 \mu \mathrm{A}$ pulses, with $7 \mathrm{sec}$ pulse and interpulse durations. After survival times of 14$21 \mathrm{~d}$, animals were perfused transcardially with $100 \mathrm{ml}$ of $0.15 \mathrm{M} \mathrm{NaCl}$, followed immediately by $400 \mathrm{ml}$ of $4.0 \%$ paraformaldehyde in $0.1 \mathrm{M}$ sodium tetraborate buffer, $\mathrm{pH} 9.5$. The brains were removed and allowed to postfix for $6-8 \mathrm{hr}$ in the final perfusate with $10 \%$ sucrose added.

Five 1 -in- 5 series of $30-\mu \mathrm{m}$-thick sections were cut through the caudal medulla on a freezing microtome. One series was mounted and the extent of the injection site and the distribution of retrogradely labeled cells were plotted using an $X-Y$ digitizer (Minnesota Datametrics). This same series was then stained with thionin and used to add nuclear boundaries.

Anterograde tracing experiments. Iontophoretic deposits of a $2.5 \%$ solution of Phaseolus vulgaris-leucoagglutinin (PHA-L, Vector Laboratories; see Gerfen and Sawchenko, 1984) in $0.1 \mathrm{M}$ sodium phosphate buffer, $\mathrm{pH} 7.4$, were made into the region of the central part of the NTS. Deposits were produced as described above, except that $+5 \mu \mathrm{A}$ current and $15 \mathrm{~min}$ injection time were used. After survival times of 7-14 d, animals were perfused and prepared for histology as described above. One series was stained with thionin and used to make projection drawings of nuclear boundaries. An adjacent series was processed for PHA-L immunoreactivity following a conventional avidin-biotin immunoperoxidase protocol (Gerfen and Sawchenko, 1984). Immunostained cells, fibers, and terminals were mapped in the medulla using camera lucida techniques.

Most animals that received PHA-L deposits also received $1 \mu$ injections of a $5.0 \%$ aqueous suspension of True blue (Dr. Illing GmbH \& Co. KG) into the sheath surrounding the vagus nerve. These deposits were made at, or slightly rostral to, the level of the nodose ganglion and retrogradely labeled cells in all subdivisions of the ambigual complex.

Immunohistochemistry. The available literature and our own material were screened in an effort to identify transmitter candidates in terminals in the rostral NA or in cell bodies in the central part of the NTS. Prosomatostatin-derived peptides appeared to meet these criteria, and antisera directed against 3 of these, somatostatin-14 (SS-14), somatostatin-28 (SS-28), and somatostatin-28 $8_{1-12}$ (SS-28 $8_{1-12}$, were used to identify the dominant molecular form(s). The sera employed were those designated S310, S309, and S320, respectively, of Benoit et al. (1982a, b), and the results of cross-adsorption studies attesting to the specificity of these sera were compatible with those provided by this (Sawchenko et al., 1988) and other (Morrison et al., 1982, 1983) laboratories. Specifically, medullary staining with each antiserum was abolished following preadsorption with $30 \mathrm{~mm}$ concentrations of the respective synthetic immunogens and was at most modestly attenuated by equimolar concentrations of the other 2 heterologous prosomatostatin-derived peptides.

Three routes of colchicine administration were used so as to give maximal enhancement of perikaryal staining in the NTS. These included direct injection of a solution containing $50 \mu \mathrm{g}$ colchicine in $25 \mu \mathrm{l}$ saline into a lateral ventricle, a similar injection into the cisternum magnum, or direct application of a pledget of Gelfoam soaked in the same solution to the dorsal surface of the medulla. Each procedure was performed 48$72 \mathrm{hr}$ prior to perfusion.

Combined anterograde tracing and immunohistochemistry. In order to evaluate the degree of correspondence between SS-28- and PHA-Lstained fibers and terminals in the rostral NA following discrete deposits of the tracer in the central part of the NTS, rabbit anti-SS-28 (serum $309,1: 3000$ dilution) and guinea pig anti-PHA-L (1:1500) were applied concurrently to series of sections through the caudal medulla. A mixture of rhodamine-conjugated goat anti-rabbit IgG (Tago, Inc., Burlington, $\mathrm{CA}$ ) and fluorescein-conjugated goat anti-guinea pig IgG (Cooper Biomedical, West Chester, PA) was used to localize primary antisera. Control procedures to assure that the secondary antisera did not crossreact with an inappropriate primary antiserum or each other were negative (see Gerfen and Sawchenko, 1985). Photographic enlargements of both SS-28- and PH $\Lambda$-L immunoreactivities were prepared of micrographs of sections taken through the rostral NA. These were photocopied onto acetate and analyzed for colocalization by transilluminating superimposed transparencies (see Gerfen and Sawchenko, 1985).

Lesion experiments. To evaluate whether the NTS is the primary source of SS-28-immunoreactive fibers and terminals in the compact part of the NA, unilateral electrolytic lesions were made in the region of the central part of the NTS. Monopolar tungsten microelectrodes (A$M$ Systems, Inc.) were positioned in the medial NTS approximately 0.5 $\mathrm{mm}$ rostral to the obex and a variable current source (model S48, Grass Medical Instruments) was used to deliver a $1.0 \mathrm{~mA} \mathrm{DC}$ current for 30 sec. After a survival time of $10 \mathrm{~d}$, animals received bilateral injections of True blue into the sheaths surrounding the vagus nerves. Three days later, the animals were perfused and prepared for localization of SS-28 immunoreactivity as described above.

\section{Results}

\section{Retrograde tracing experiments}

Eight deposits of FG were obtained that were centered over the rostral part of the NA (Fig. 1). In each case, retrogradely labeled cells were found in the medial, lateral, and commissural subdivisions of the NTS, with one prominent cluster of loosely organized cells situated ventrolateral and another far more compact grouping found ventromedial to the solitary tract (Figs. 1, 2). Those cells found ventrolateral to the solitary tract appear to correspond to those described by Loewy and Burton (1978) in the cat and Ross et al. (1985) in the rat as projecting to the ventrolateral medulla, and they occupy the ventrolateral and ventral subnuclei of the NTS as described by Kalia and Sullivan (1982). Those cells found ventromedial to the solitary tract cor- 

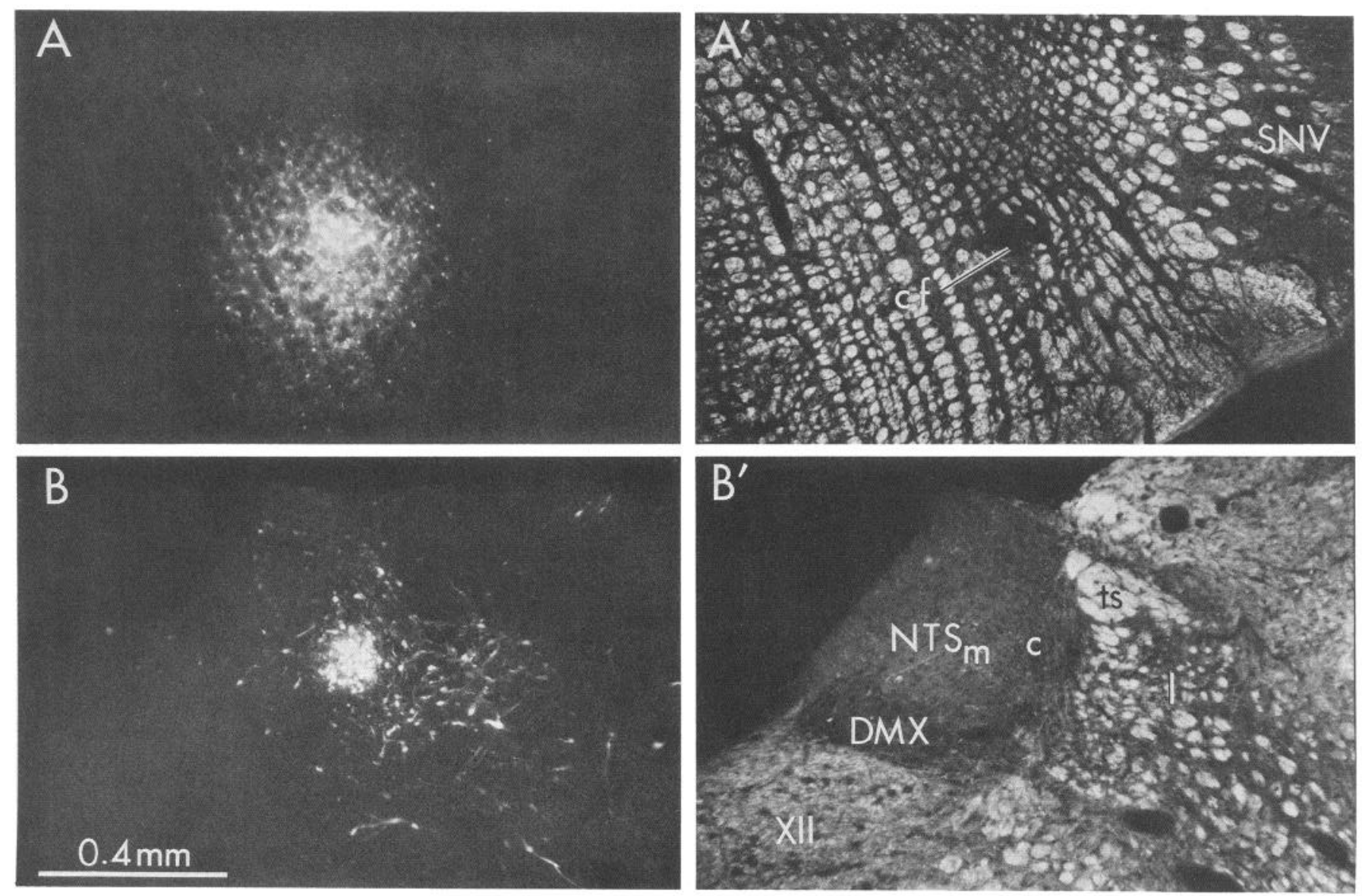

Figure 1. Fluorescence photomicrographs to show retrograde labeling in the central part of the NTS $(B)$ resulting from a deposit of FG centered in the rostral NA $(A)$. Dark-field photomicrographs of the same sections are shown to provide a reference for cyto- and myeloarchitecture in the ventrolateral $\left(A^{\prime}\right)$ and dorsomedial $\left(\mathrm{B}^{\prime}\right)$ medulla.

respond to a cell group described in the rat by Bieger (1984), Stuesse and Fish (1984), and Ross et al. (1985) as projecting to the region of the rostral part of the NA. This cell group has not been described in Nissl material (see Kalia and Sullivan, 1982) but appears to lie in what has been termed the medial subnucleus. Given that we found this cell group to be discriminable in Nissl-stained material and strikingly circumscribed with regard to its projections, we follow Ross et al. (1985), who distinguished it from the medial subnucleus and referred to it as the central subnucleus, or part, of the medial NTS.

In Nissl-stained material, the central part of the NTS formed a column of cells immediately ventromedial to the solitary tract and extending from about 300 to $1000 \mu \mathrm{m}$ rostral to the obex. It was composed of small, round to oval-shaped neurons, typically $6-10 \mu \mathrm{m}$ in diameter. Virtually all of these cells were retrogradely labeled by injections of FG centered in the rostral NA (Figs. 1, 2).

Deposits of FG centered near but not within the rostral part of the NA $(n=20)$ failed to label cells in the central part of the NTS, although other parts of the nucleus were labeled. In particular, numerous labeled cells were observed in the caudal half of the NTS, including its lateral, medial, and commissural subdivisions (E. T. Cunningham and P. E. Sawchenko, unpublished observations; see also Loewy and Burton, 1978; Ross et al., 1985).

\section{Anterograde tracing experiments.}

Fourteen animals received deposits of PHA-L in the central part of the NTS that resulted in dense and topographically restricted projections to the rostral part of the NA (Figs. 3, 4). In the majority of these cases, very few other structures in the brain received inputs, with the exception of moderate projections to the dorsal motor nucleus of the vagus (Fig. 4) and the lateral parabrachial nucleus (not shown). However, these projections may have arisen from cells outside of the central part of the NTS, as even the most restricted deposits involved a few such cells. In fact, 8 experiments in which deposits of FG were placed in the lateral parabrachial nucleus failed to label cells in the central part of the NTS (Cunningham and Sawchenko, unpublished observations).

Projections from the central part of the NTS traversed the medullary reticular formation as fairly straight, unbranched axons with regularly spaced varicosities. In the region of the rostral part of the NA, these fibers arborized extensively, giving rise to numerous terminal varicosities that appeared to wrap around ambigual motor neurons (Fig. 4). Very sparse projections were seen to other regions of the ventrolateral medulla, including the palatopharyngeal, laryngeal, and cardiac portions of the NA (Fig. 5). No projections were observed to the contralateral compact formation. 


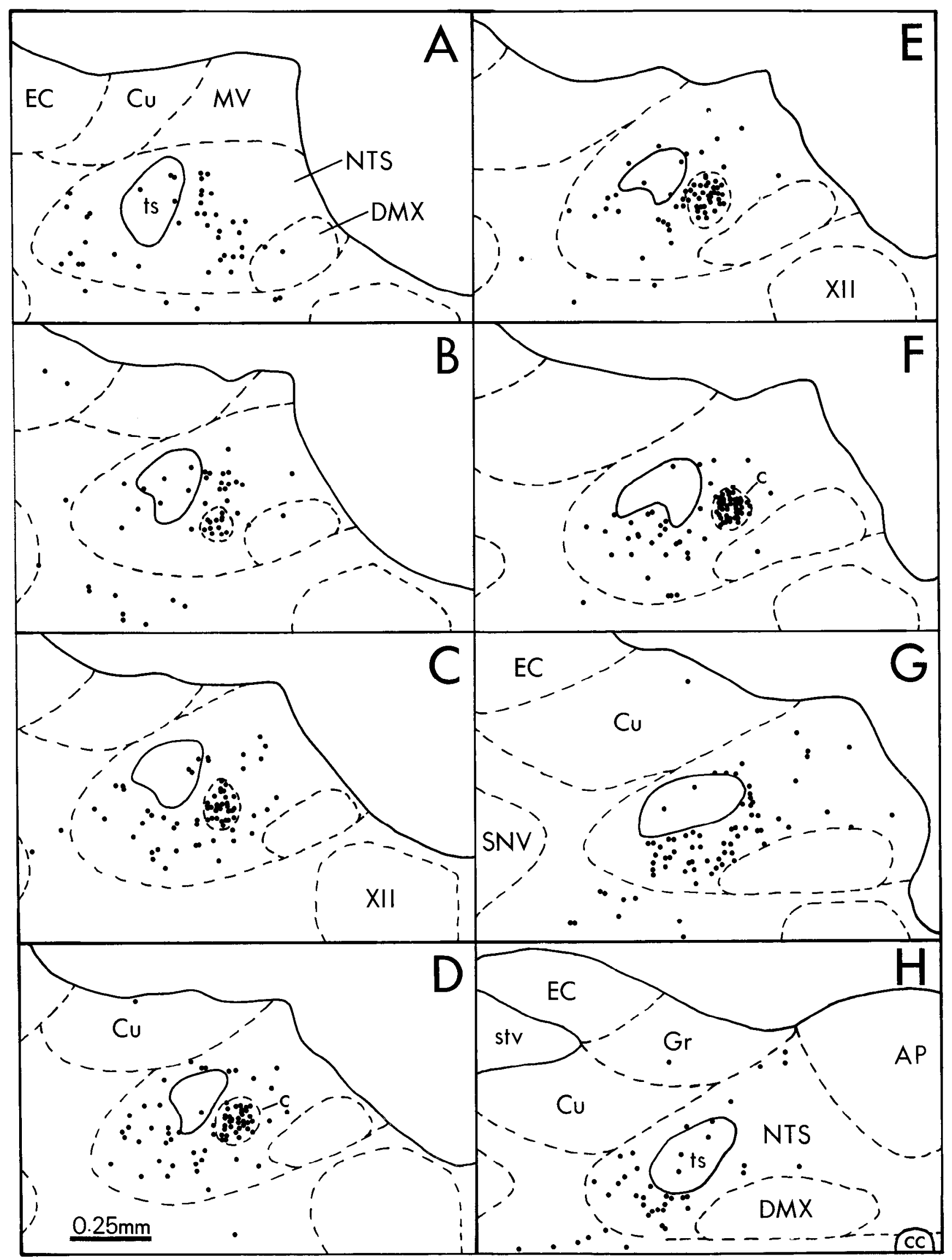

Figure 2. Series of closely spaced line-drawings through the dorsomedial medulla to show the location and extent of retrogradely labeled neurons in the NTS following a discrete iontophoretic deposit of FG in the rostral part of the NA. The most rostral section $(A)$ is about $1200 \mu \mathrm{m}$ rostral to the obex, and more caudal sections are approximately $150 \mu \mathrm{m}$ apart. Note the location of the central part of the NTS $(c)$ in parts $B-F$. Notc also the high density of retrogradely labeled neurons in this part of the nucleus. 

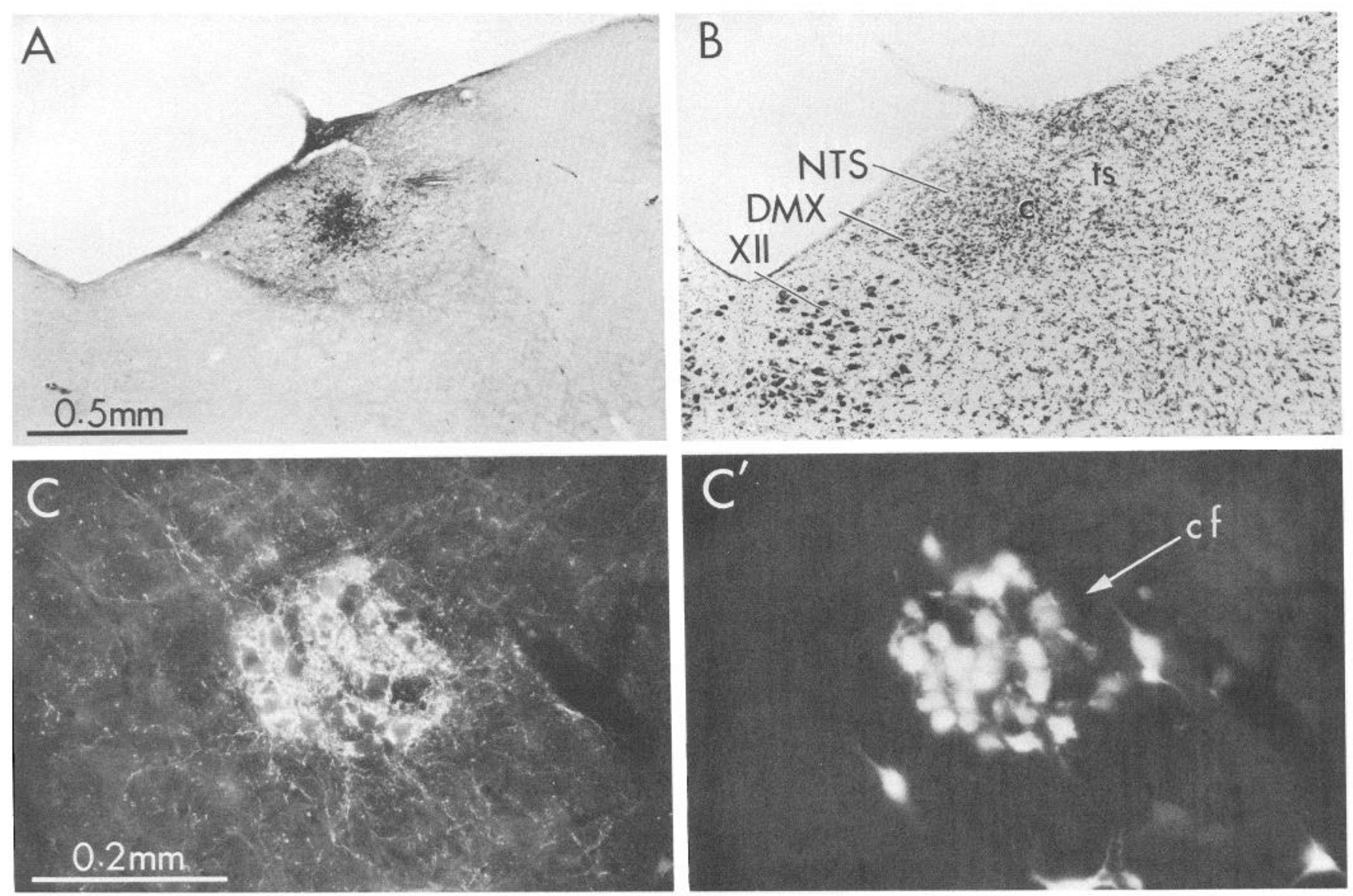

Figure 3. Bright-field photomicrographs showing a representative PHA-L injection site in the central part of the NTS $(A)$ in relation to an adjacent Nissl-stained section $(B)$. Fluorescence photomicrographs show the resultant terminal field in the rostral, compact, part of the NA $(C)$ in relation to ambigual motor neurons in the same section retrogradely labeled by an injection of True blue in the vagus nerve at a high cervical level $(C)$.

Numerous deposits of PHA-L placed ventrolateral $(n=6)$ or medial to the solitary tract $(n=19)$, but not involving the central part of the NTS, gave rise to sparse inputs to the rostral part of the NA. There were, however, moderate to heavy projections to other aspects of the ventrolateral medulla, including nonesophageal parts of the ambigual complex (Fig. 6), the facial nucleus, and regions known to contain catecholaminergic neurons of the $\mathrm{Al}$ and $\mathrm{Cl}$ cell groups (not shown).

\section{Somatostatin immunohistochemistry}

Of the 3 antisera evaluated, S309 (raised against SS-28) provided the most robust staining of fibers in the rostral NA (Figs. 8, 9; see also Finley et al., 1981; Johansson et al., 1984). Staining for SS-28 in other aspects of the ambigual complex was far less intense. Terminals in rostral NA stained less robustly for SS$28_{1-12}$ and extremely weakly for SS-14.

Although both intraventricular and intracisternal pretreatments with colchicine were effective in enhancing perikaryal staining for SS-28 in most parts of the NTS (see also Finley et al., 1981; Johansson et al., 1984; Millhorn et al., 1987a; Sawchenko et al., 1988), few cells were demonstrable in the central part of the nucleus. Direct application of colchicine-soaked pledgets to the dorsal surface of the medulla did, however, show as many as one-third of the cells in the central part of the NTS to be SS-28 immunoreactive (Fig. 7). It should be noted that, even in the best cases, the majority of cells in the central part of the NTS were immunonegative for SS. Under all conditions, cellular staining for SS-28 within the central subnucleus was far more prominent than for either SS-14 or SS-28 ${ }_{1-12}$, which stained at most 1 or 2 cells per section.

\section{Combined anterograde tracing-immunohistochemical staining studies}

The large proportion of neurons in the central part of the NTS that were retrogradely labeled following deposits of FG in the region of the rostral NA, taken together with the presence of at least some SS-28-immunoreactive neurons in this part of the NTS, is itself suggestive that this pathway might be partly somatostatinergic. In addition, however, we have examined 6 cases that received PHA-L deposits centered in the central part of the NTS for the presence of SS-28 immunoreactivity in anterogradely labeled fibers and terminals. Dual staining for PHA-L and SS-28 revealed strikingly similar distributions of the 2 markers throughout the ambigual complex. Moreover, in each experiment an appreciable number of PHA-L-labeled fibers and terminals were found to be SS-28 immunoreactive (Figs. 8, 9). It was often the case that staining for one or both markers was so dense that decisive resolution of individual varicosities was obscured (Fig. 9).

\section{Lesion experiments}

Despite the fact that the dual-labeling studies suggested that the central part of the NTS constitutes the major source of SS-28immunoreactive projections to the compact NA, the nonquan- 

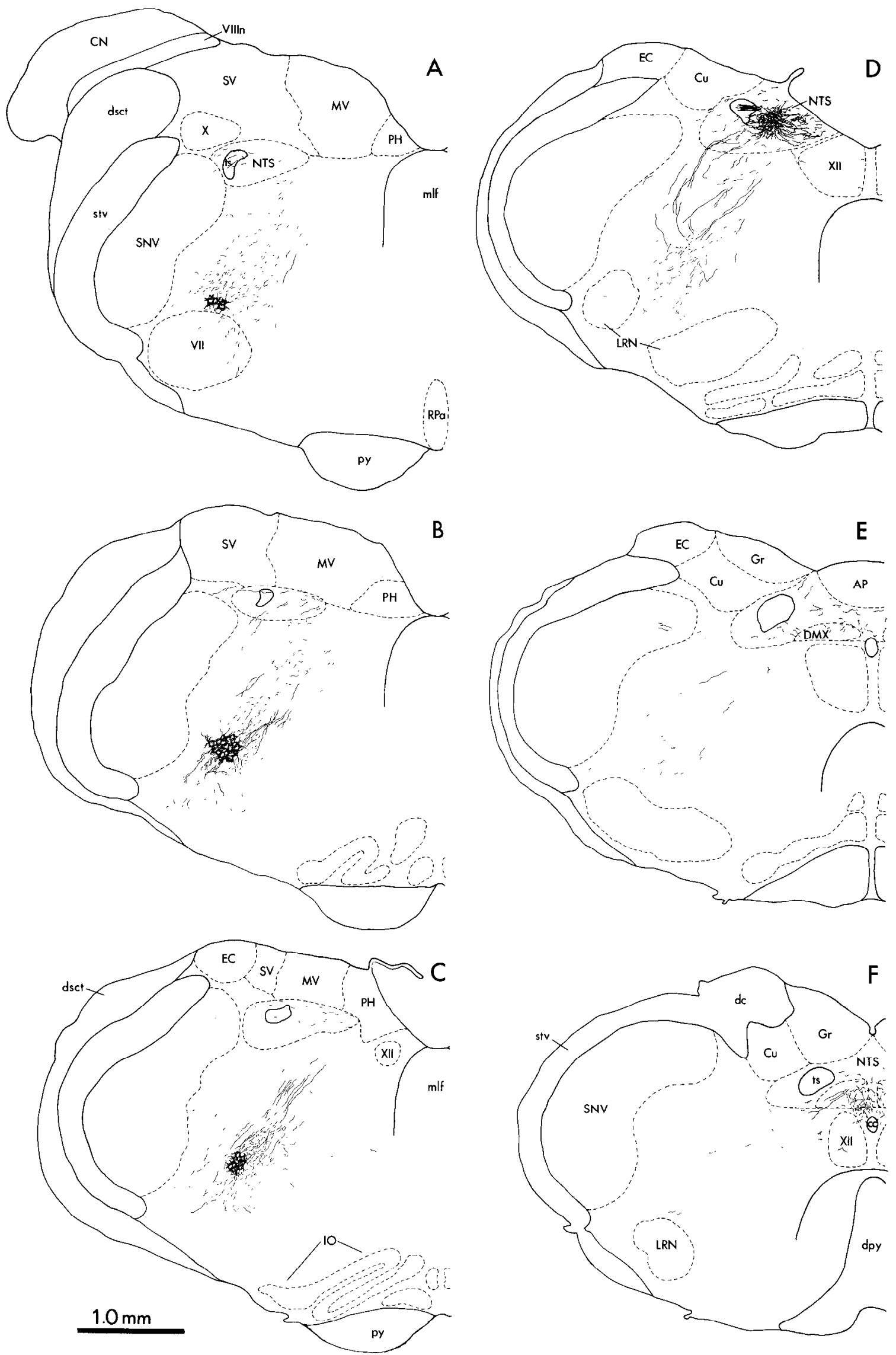

Figure 4. Series of evenly spaced line drawings through the caudal brain stem to show the distribution of anterograde labeling following a discrete iontophorectic deposit of PHA-L in the central part of the NTS. The center of the injection site is show in $D$. Note the dense terminal field in the ventrolateral medulla, in the rostral part of the NA. The only other terminal ficld of any prominence is in the dorsal motor nucleus of the vagus nerve. Sections are arranged from rostral $(A)$ to caudal $(F)$ at approximately $600 \mu \mathrm{m}$ intervals. 

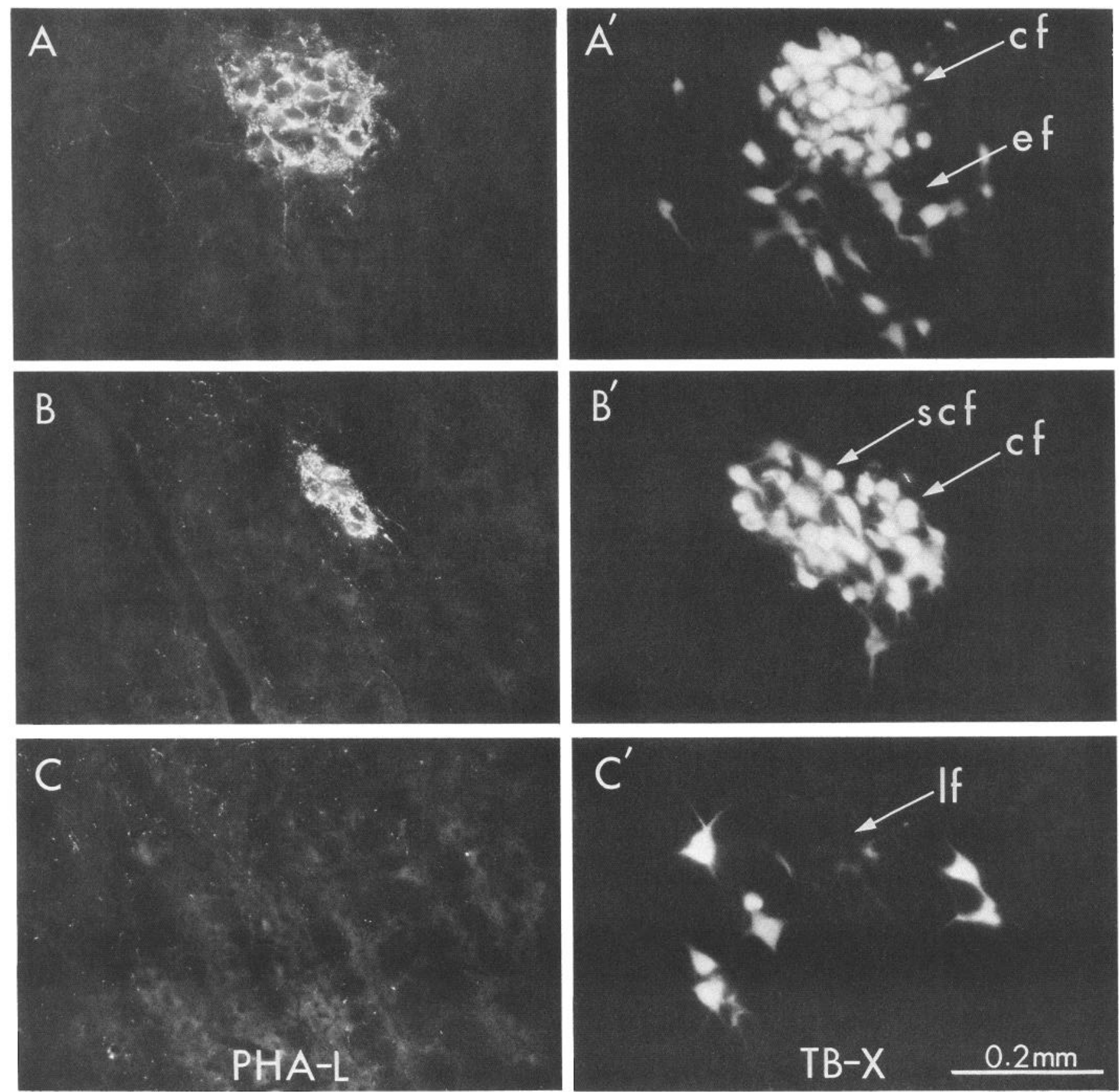

Figure 5. Series of fluorescence photomicrographs through various rostrocaudal levels of the ambigual complex to show the distribution of anterograde label (PHA-L) arising from the central part of the NTS in relation to various subdivisions of the NA, labeled here by an injection of True blue in the vagus nerve $(T B-X)$. Note the dense and topographically restricted projection to the compact formation (cf), while other aspects of the NA receive at most sparse inputs.

titative nature of the method leaves open the possibility that a significant portion of the somatostatinergic input might arise from sources other than the NTS. We therefore placed unilateral electrolytic lesions in the medial NTS and examined for their effects on SS-28 staining in the rostral NA. In 3 animals, lesions destroyed the medial NTS from about 0.2 to $2.0 \mathrm{~mm}$ rostral to the obex. In addition, a portion of the ventrolateral NTS, as well as the gracile and hypoglossal nuclei, were consistently involved. The commissural NTS and the entire contralateral side were undamaged. In each of these cases, SS-28 immunoreactivity was markedly decreased in the ipsilateral compact NA, while staining on the contralateral side was robust, and comparable to that seen in intact controls (Fig. 10).

\section{Discussion}

The results of the present study provide new information on the topography and transmitter specificity of the projection from the NTS to the ambigual complex. Retrograde and anterograde 

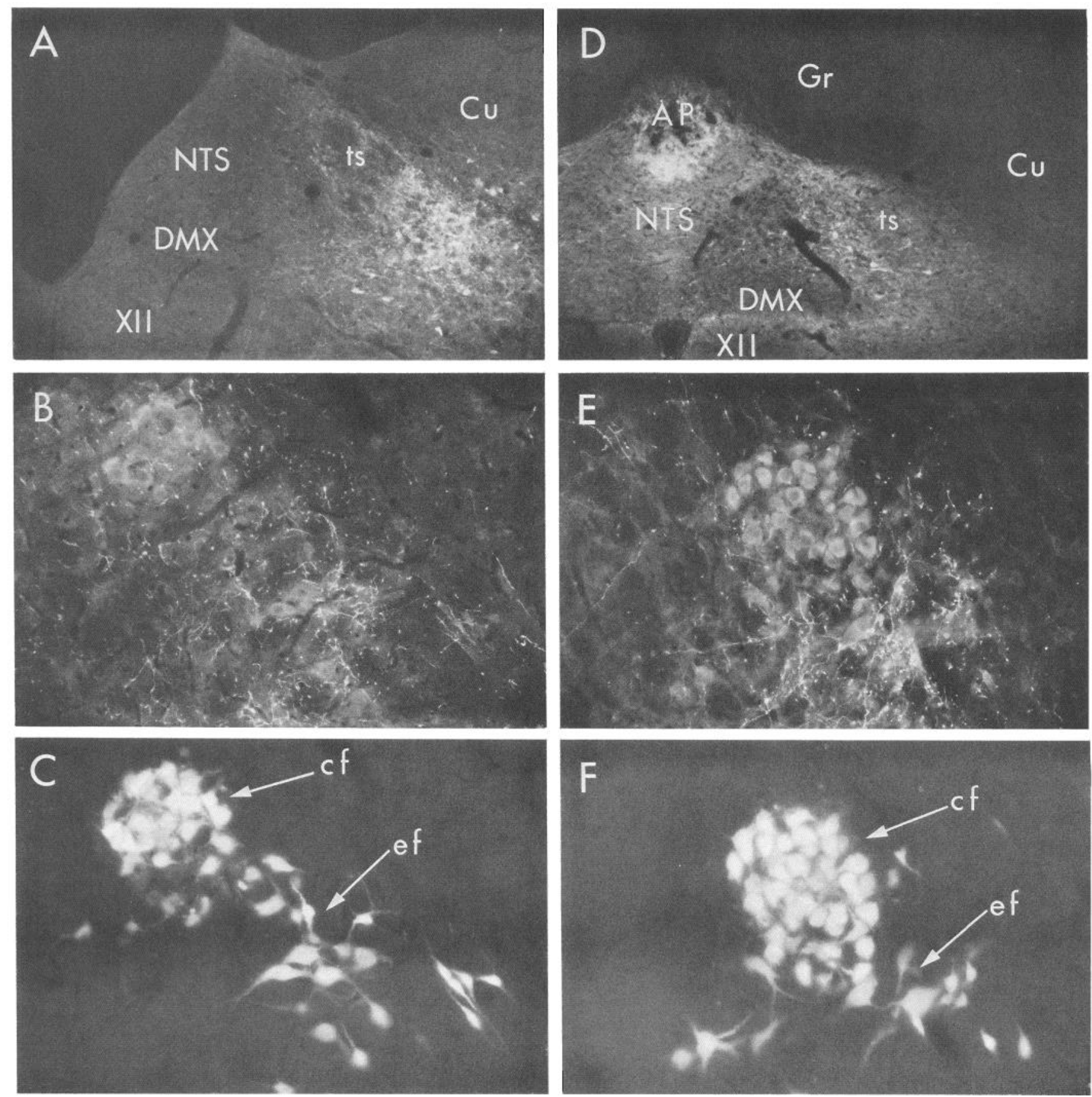

Figure 6. Fluorescence photomicrographs of control injections of PHA-L not involving the central part of the NTS, and the resultant terminal field in the region of the rostral NA. Injections placed in the lateral part of the NTS $(A)$ resulted in moderately dense terminal fields in the ventrolateral medulla but only sparse inputs to the compact formation $(B$ and $C)$. Similarly, injections placed in the medial part of the NTS $(D)$ gave rise to appreciable anterograde labeling but only light inputs to the esophageal part of NA $(E$ and $F)$.

tracing experiments defined a discrete, central, part of the medial subdivision of the NTS that gives rise to a dense and topographically restricted projection to the rostral NA. In addition, SS28 immunoreactivity was demonstrated in cells in the central part of the NTS and in their projections to the rostral NA. These results provide evidence for some measure of anatomical and biochemical dissociability of projections from the NTS to the ventrolateral medulla and identify a potential substrate for the reflex control of esophageal motility.
Topographic organization of NTS projections to the ambigual complex

Though numerous studies have demonstrated projections from the NTS to the ventrolateral medulla, there exists little information as to the topographic or biochemical specificity of inputs to this region, particularly with respect to the subnuclear organization of the NA. Noteworthy in this regard were the results of retrograde transport experiments suggesting the existence of 

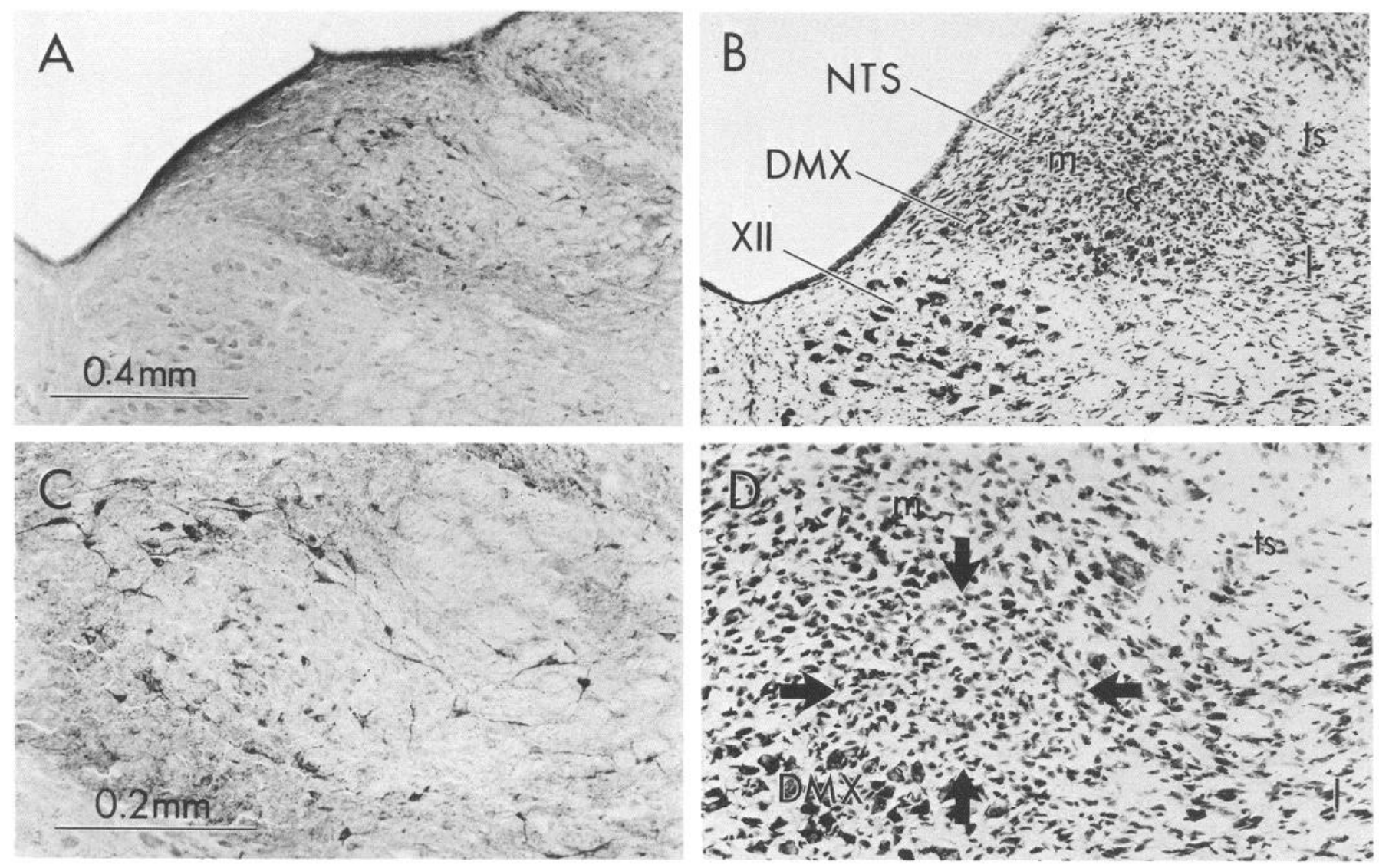

Figure 7. Bright-field photomicrographs to show SS-28-immunostaining in the central part of the NTS ( $A$, low power, and $C$, high power) in relation to an adjacent Nissl-stained section ( $B$, low power, and $D$, high power). Animals were pretreated with colchicine-soaked pledgets applied directly on the dorsal surface of the medulla $48-72 \mathrm{hr}$ before perfusion.

a projection from the central part of the NTS to the rostral part of the NA (Bieger, 1984; Stuesse and Fish, 1984; Ross et al., 1985). While these authors did not directly examine the possibility that the central part of the NTS might project to other aspects of the ventrolateral medulla or NA, they did describe numerous retrogradely labeled cells in the central part of the NTS following deposits of retrograde tracer in the region of the rostral NA.

Similarly, anterograde tracing studies employing the autoradiographic method suggested the existence of widespread projections from the NTS to the ventrolateral medulla, which included the region of the NA (Loewy and Burton, 1978; Norgren, 1978; Ricardo and Koh, 1978; Beckstead and Norgren, 1980; Sawchenko and Swanson, 1982; Ross et al., 1985). Ross and colleagues, in particular, showed a dense projection to the rostral part of the ambigual complex. In each of these cases, however, tracer deposits in the NTS were fairly large, involving aspects of its medial, lateral, and commissural subdivisions, and resulted in relatively diffuse anterograde labeling throughout the medullary reticular formation. Moreover, the resolution afforded by the autoradiographic method did not provide information on the morphology of fibers and terminals, and could not, therefore, resolve terminal fields form fibers-of-passage with certainty.

The present study confirms the findings of these earlier studies and extends them in several ways. First, our retrograde transport studies have defined the extent of the central part of the NTS. We found it to comprise a column of cells situated immediately ventromedial to the solitary tract and extending from about 300 to $1000 \mu \mathrm{m}$ rostral to the obex. In addition, the vast majority of cells in the central part of the NTS were found to project to the region of the rostral NA. Second, our anterograde tracing studies have provided the first demonstration of a discrete projection from the central part of the NTS to the rostral NA, and the resolution afforded by the PHA-L technique strongly suggests that anterogradely labeled fibers and terminals are interacting synaptically with esophageal motor neurons. Third, we have shown that other aspects of the NTS that do project to the ventrolateral medulla, including portions of the ambigual complex, project only sparsely to the rostral NA. This suggests that projections from the NTS to the various effector neuron pools in the ventrolateral medulla may well be anatomically and/or biochemically distinct and dissociable.

\section{Transmitter specificity}

Although numerous neuroactive agents have been localized to fibers and cell bodies in the NTS (see Maley and Elde, 1982; Kalia et al., 1984; Yamazoe et al., 1984; Leslie, 1985; Palkovits, 1985; Miura et al., 1987; and Diz et al., 1987, for reviews), none has been localized with regard to the central part of the nucleus. Given the presence of somatostatin-immunoreactive cell bodies in the medial part of the NTS (Finley et al., 1981; Johansson et al., 1984; Millhorn et al., 1987a) and of a dense somatostatinimmunoreactive terminal field in the rostral part of the NA (Finley et al., 1981; Johansson et al., 1984), we began a search for candidate constituents with somatostatin. 

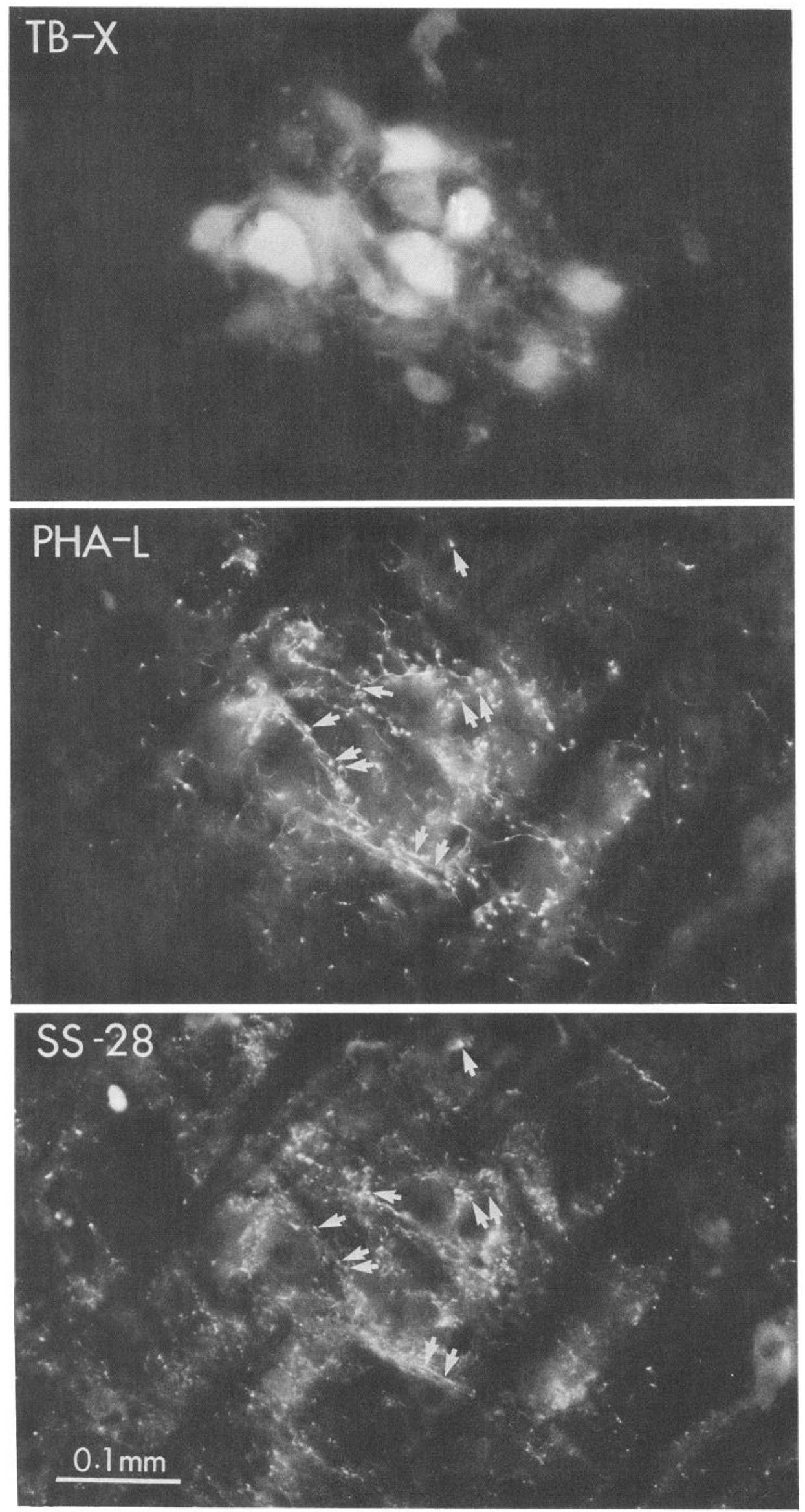

Figure 8. Series of fluorescence photomicrographs through the rostral part of the NA to show neurons in the compact formation, retrogradely labeled by an injection of True blue in the vagus $(T B-X)$, in relation to fibers and terminals anterogradely labeled by an injection of PHA-L in the central part of the NTS and the endogenous SS-28-immunoreactive terminal field. Note the general similarity in the distribution of PHA-L and SS-28 immunostaining. Some examples of individual varicosities in which immunoreactivity for tracer and peptide were colocalized are indicated (arrows). 


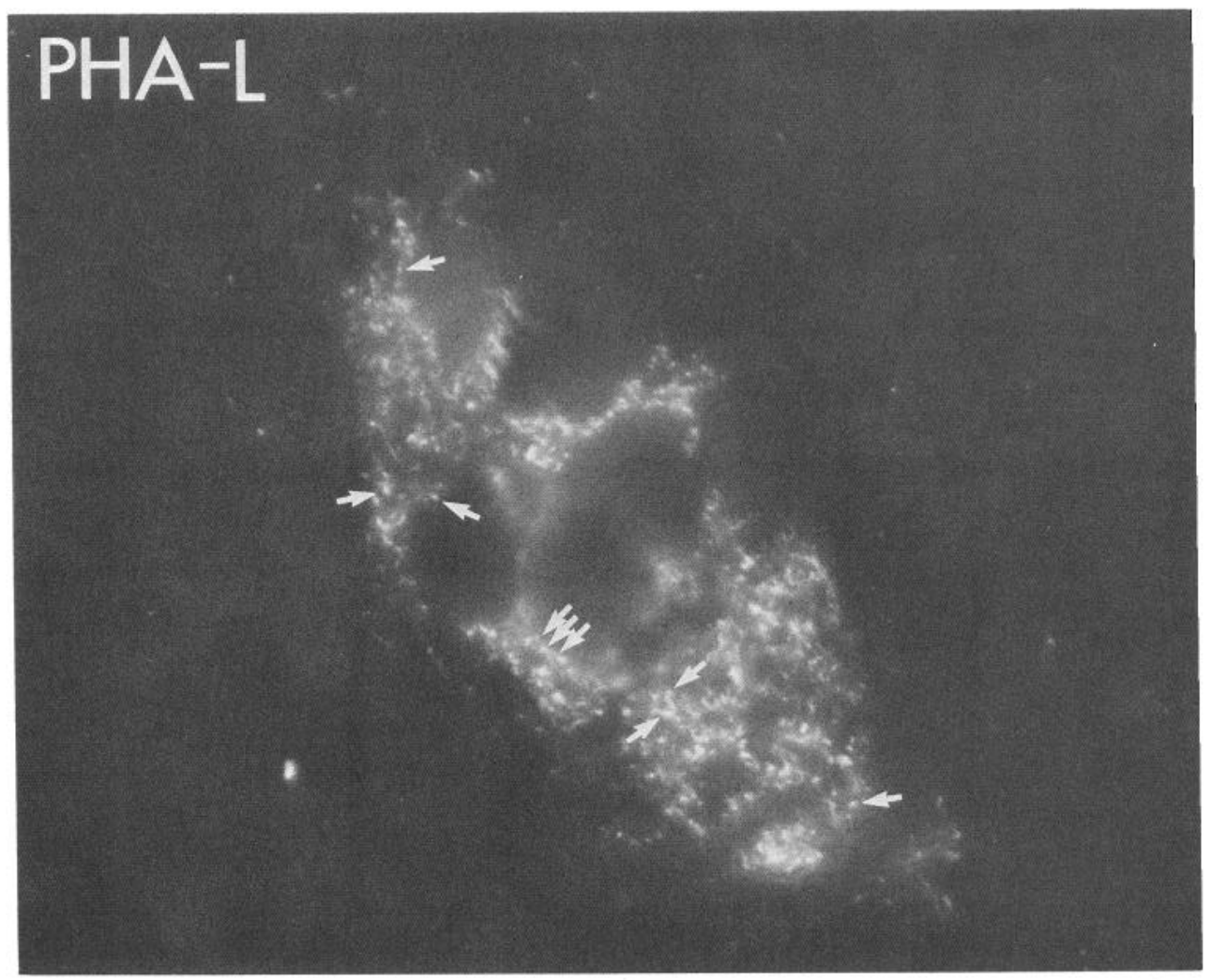

Figure 9. Fluorescence photomicrographs through the rostral part of the NA to show the similarity in the distribution of fibers and terminal fields anterogradely labeled from the central part of the NTS (PHA-L) and those displaying endogenous SS-28 immunoreactivity. Examples of varicosities stained for both markers are indicated

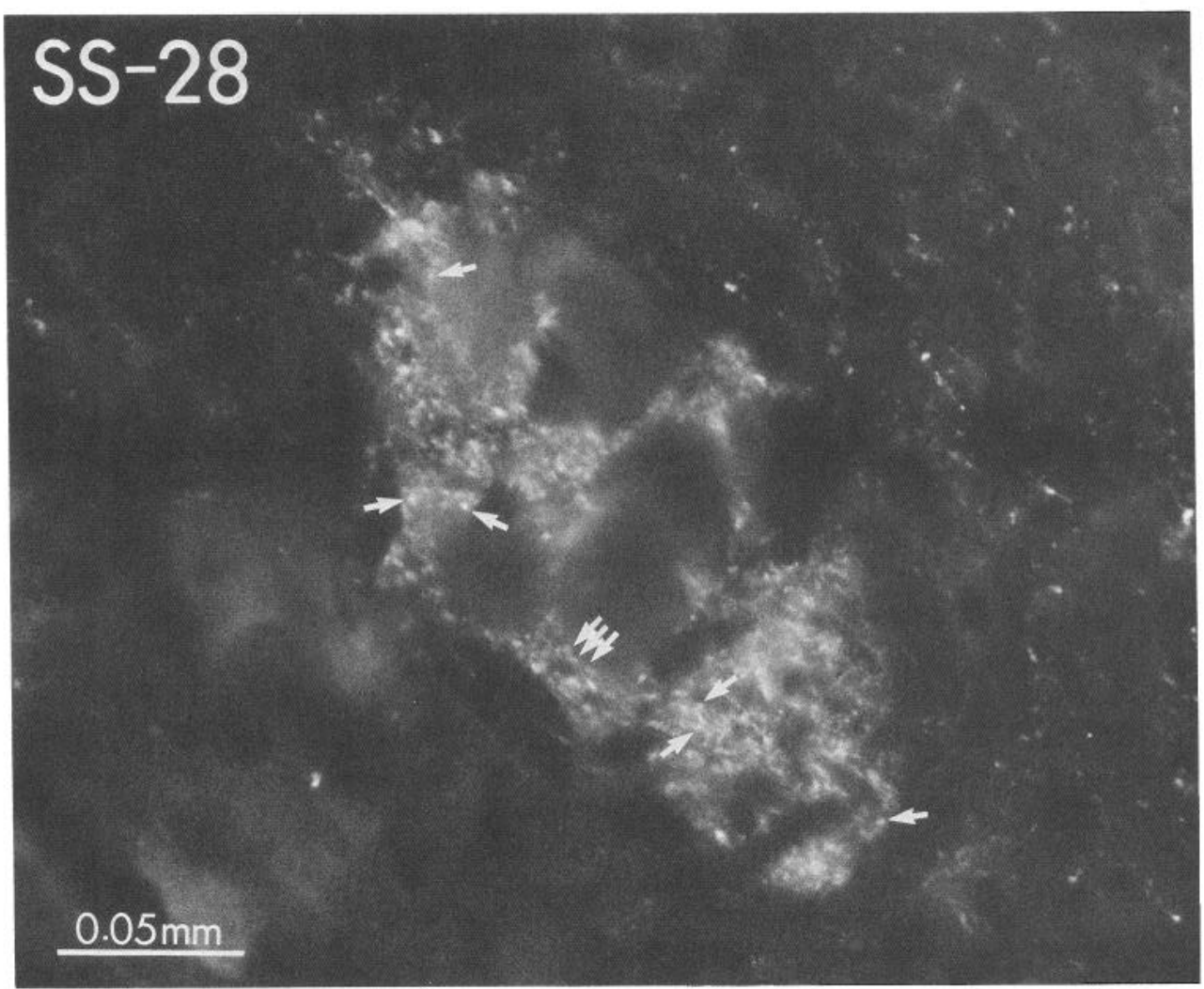
(arrows).

Perikaryal staining was greatly enhanced in the NTS following application of colchicine-soaked pledgets to the dorsal surface of the medulla. Even with this, however, somatostatin-immunoreactive perikarya were difficult to demonstrate in the central part of the NTS. This is problematic in light of the relatively dense terminal field in the NA, which appears to arise in large measure from the central NTS. Precedents for such disparities between perikaryal and associated terminal labeling may be cited (Kuljis and Karten, 1986) and could be explained by rapid axonal transport and/or relatively low rates of synthesis. 

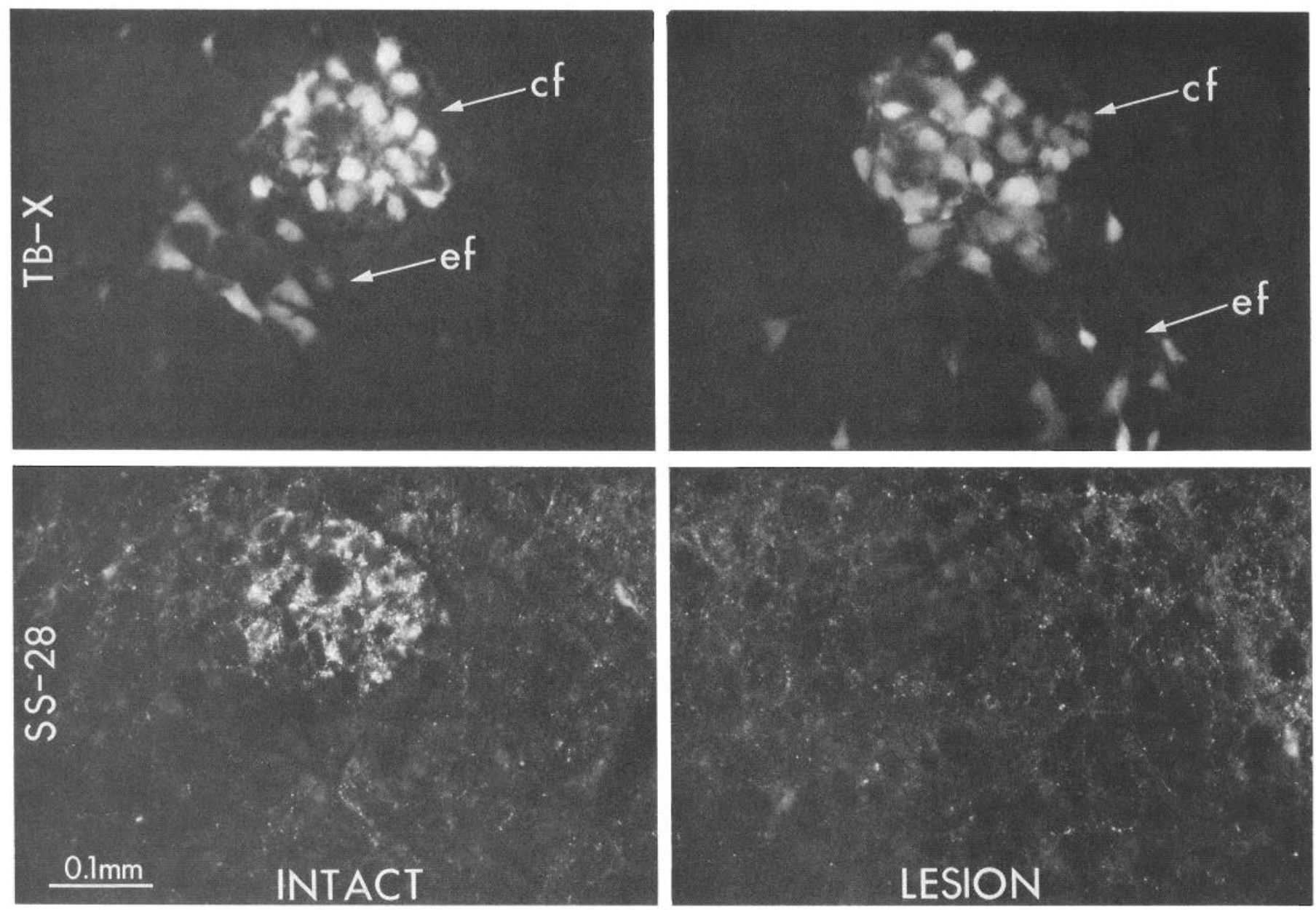

Figure 10. Series of fluorescence photomicrographs through the ventrolateral medulla to show the effect of a unilateral electrolytic lesion of the NTS, which included the central subnucleus, on SS-28 staining in the compact part of NA. Ambigual motor neurons were labeled by bilateral injection of True blue in the vagus nerves $(T B-X)$. SS-28 immunoreactivity is markedly reduced ipsilateral to the lesion $(L E S I O N)$, whereas staining is unchanged on the contralateral (INTACT) side.

The use of well-characterized antisera that preferentially recognize 3 distinct prosomatostatin-derived peptides suggested that the dominant molecular form expressed in the NTS-compact NA pathway is SS-28. Sera directed against SS-14 and SS$28_{1-12}$ both stained perikarya and fibers in this system, but far less robustly than the one raised to SS- 28 . This contrasts with results obtained using these same sera in cortical structures, where SS- $28_{1-12}$ clearly appears to predominate in fibers (Morrison et al., 1982, 1983), and suggests some measure of regional specificity in the processing of prosomatostatin.

The combined anterograde transport-immunohistochemical approach employed here is not a quantitative method (see discussion in Levin et al., 1987). However, the similarity in density and distribution of PHA-L- and SS-28-labeled fibers, the extent to which SS-28-immunoreactivity could be colocalized within anterogradely labeled fibers arising from the central part of the NTS, and the results of the lesion experiments, all converge to support the conclusion that the pathway is, at least in part, somatostatinergic. Extrinsic (i.e., non-NTS) sources appear not to contribute substantially to this pathway. It remains to be determined whether other candidate transmitters exist within those perikarya of the central part of the NTS that failed to stain for prosomatostatin-derived peptides.

\section{Conclusions}

While the importance of the CNS in coordinating swallowing has been known for some time (Meltzer, 1899, 1907; see also Sumi, 1964; Doty, 1968; Miller, 1982, 1986, 1987; and Jean, 1984 , for reviews), it is only recently that distinct parts of the brain stem have been implicated in establishing and maintaining specific components of this behavior. In particular, numerous studies in sheep (Jean, 1972a, b, 1978; Amri et al., 1984) have identified 3 regions of the medulla from which swallowing-related activity may be recorded. The first of these is in and around the lateral subdivision of the NTS, slightly rostral to the obex. Most of the cells in this region display a burst of activity in the initial phase of swallowing, just prior to the contraction of the pharyngeal musculature. A second group of cells is situated in the ventrolateral medulla, in and around the NA, and shows increased neuronal activity during pharyngeal contraction, in the so-called pharyngeal phase. As might be expected, many of these cells appear to be ambigual motor neurons innervating the pharynx, as they were able to be activated antidromically by stimulating the cervical vagus nerve (Jean, 1972a). Finally, a third group of cells, whose activity increases late, during the esophageal phase, is situated medial to the solitary tract, in the 


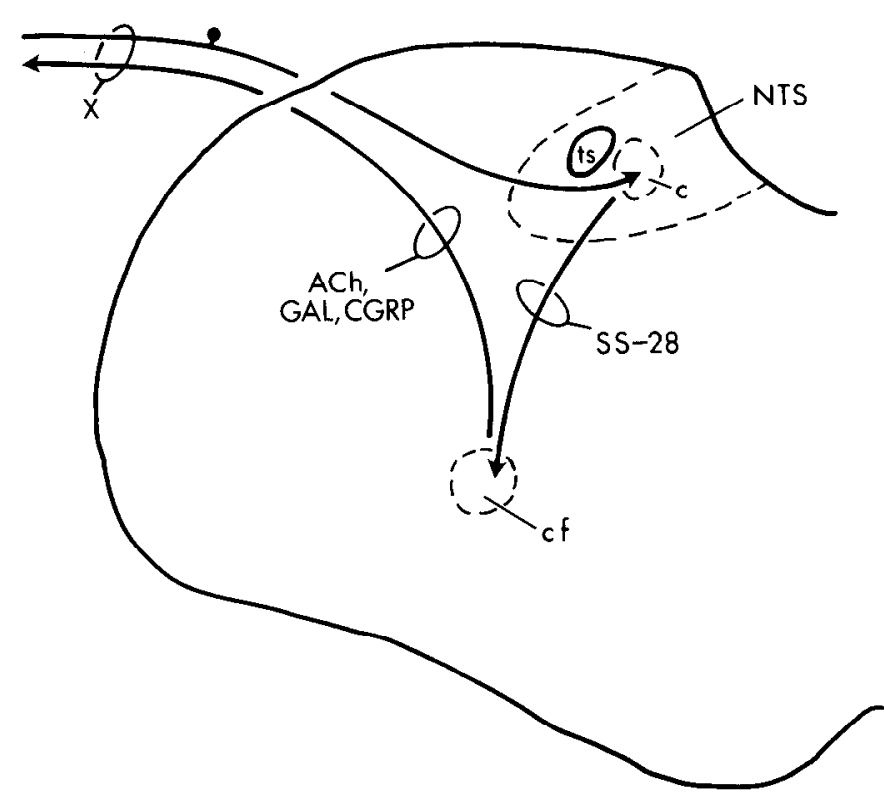

Figure 11. Schematic drawing of a coronal hemisection through the medulla to illustrate the proposed reflex arc. Esophageal sensory information is brought into the central part of the NTS via the vagus nerve $(X)$. The central part of the NTS, in turn, sends a dense, partly somatostatinergic, projection to the rostral, or compact, part of the NA. The arc is completed by esophageal motor neurons in the rostral NA, which, in addition to $(A C h)$, have been show to contain both galanin $(G A L)$ and calcitonin gene-related peptide (CGRP).

general region of the central part of the NTS. Lesions involving this third group preferentially disrupt (Jean, 1972b), while focal glutamate stimulation preferentially elicits (Bieger, 1984), the esophageal phase of swallowing (see Miller, 1986, for review). Moreover, esophageal afferents have recently been shown to terminate in the region of the central part of the NTS (Fryscak et al., 1984; Altschuler et al., 1988). It would appear, therefore, that the most likely role for a central NTS-rostral NA projection is that of an interneuron linking primary afferents with the motor supply of the esophagus, and thus participating in the control of sccondary esophagcal peristalsis. Wc arc aware of no more anatomically well-defined circuitry for a viscus-specific reflex in the mammalian brain stem.

The presence of SS, a peptide best known for its hypophysiotropic role in the inhibition of growth hormone secretion, in esophageal reflex circuitry is somewhat unexpected, though its widespread distribution in functionally unrelated parts of the brain (Finley et al., 1981; Johansson et al., 1984) would seem to rule out the existence of any unified system with which SS has an a priori association. In fact, even within the NTS, SS28 has been localized in a projection from the commissural part of the nucleus to the neurosecretory hypothalamus (Sawchenko et al., 1988), a pathway ostensibly unrelated to swallowing.

Physiologically, the majority of intracellular studies have described SS as hyperpolarizing (see Siggins and Groul, 1986, for review), and similar effects have been described for vagal motor neurons in the dorsal medulla (Oomura and Mizuno, 1986; G. Siggins, personal commmunication). Somatostatin has, however; been shown to enhance the excitatory effects of $\mathrm{ACh}$ in the hippocampus and neocortex (Mancillas et al., 1986), and it could serve a similar, modulatory, function in the brain stem. This notion gains some support from recent reports of widespread colocalization of SS with enkephalin-like peptides in cells in the caudal medulla, including some aspects of the NTS (Millhorn et al., 1987a, b). Thus, while the results identify SS-28 as a marker for circumscribed central NTS-rostral NA projection, its role in synaptic transmission, as well as those of any coexisting principles, remain to be clarified.

The present results, viewed in conjunction with other recent anatomical and biochemical findings, bring us closer to defining the circuitry for a relatively closed-loop reflex in the caudal medulla, in which SS-28-immunoreactive cells in the central part of the NTS serve as interneurons in the broadest sense of the term (Fig. 11; see Jankowska, 1987). In addition to $\mathrm{ACh}$ (c.g., Houser et al., 1983; Kimura et al., 1984), both galanin (GAL; Sawchenko et al., 1987) and calcitonin gene-related peptide (CGRP; Rosenfeld et al., 1983; Kawai et al., 1985) have been described in cells in the compact part of the NA. Moreover, fibers and terminals immunopositive for GAL (Sengupta and Goyal, 1988) and CGRP (Rodrigo et al., 1985) have been described in the esophagus, and CGRP has been localized within Inotor end plates. To date, no transmitter or transmitter-candidate has been described in esophageal afferents, although glutamate (see Talman et al., 1984) and a number of peptides (see Dockray and Sharkey, 1986) have been described in vagal sensory systems in general. Recent descriptions (Altschuler et al., 1988) of esophageal afferents ending preferentially in the central part of the NTS indicate that this issue may now be approachable.

In summary, we have provided evidence for somatostatinergic interneurons projecting from the central part of the NTS to the rostral, compact, part of the NA. Together with anatomical and physiological studies implicating the central part of the NTS and the rostral NA in esophageal function, these data provide support for a disynaptic, closed-loop pathway subserving reflex control of esophageal motility. Immunohistochemical studies suggest the biochemical specificity of various components of this proposed loop to be more complex than at first expected.

\section{Appendix}

\section{Abbreviations for figures}

$A C h$, acetylcholine; $A P$, area postrema; $c c$, central canal; $C G R P$, calcitonin gene-related peptide; $c f$, compact formation (nucleus ambiguus); $C N$, cochlear nucleus; $C u$, cuneate nucleus; $d c s t$, dorsal spinocerebellar tract; $D M X$, dorsal motor nucleus of the vagus; $d p y$, decussation of the pyramidal tracts; $E C$, external cuneate nucleus; ef, external formation (nucleus ambiguus); $G A L$, galanin; ( $G r$, gracile nucleus; $I O$, inferior olivary nucleus; $l f$, loose formation (nucleus ambiguus); $L R N$, lateral reticular nucleus; $m l f$, medial longitudinal fasciculus; $M V$, medial vestibular nucleus; $N T S$, nucleus of the solitary tract; $N T S_{c}$, central part of the NTS; NTS, lateral NTS; NTS, medial NTS; $P H$, nucleus prepositus hypoglossi; PHA-L, Phaseolus vulgaris-leucoagglutinin; $p y$, pyramidal tract; $R P a$, nucleus raphe pallidus; $s c f$, semicompact formation (nucleus ambiguus); $S L N$, superior laryngeal nerve; $S N V$, spinal nucleus of the trigeminal nucleus; $S S-28$, somatostatin-28; stv, spinal tract of the trigeminal nucleus; $S V$, spinal vestibular nucleus; $T B-X$, True blue in the cervical vagus; $t s$, solitary tract; VII, facial nucleus; VIIIn, eighth nerve; $X$, nucleus $X ; X I I$, hypoglossal nucleus.

\section{References}

Altschuler, S. M., X. Bao, D. Bieger, D. A. Hopkins, and R. R. Miselis (1988) Viscerotopic representation of the upper alimentary tract in the rat: Sensory ganglia and nuclei of the solitary and spinal trigeminal tracts. J. Comp. Neurol. (in press).

Amri, M., A. Car, and A. Jean (1984) Medullary control of the pontine swallowing neurones in sheep. Exp. Brain Res. 55: 105-110.

Beckstead, R. M., J. R. Morse, and R. Norgren (1980) The nucleus 
of the solitary tract in the monkey: Projections to the thalamus and brain stem nuclei. J. Comp. Neurol. 190: 259-282.

Benoit, R., P. Bohlen, N. Ling, A. Briskin, F. Esch, P. Brazeau, S.-Y. Ying, and R. Guillemin (1982a) Presence of somatostatin $28_{1-12}$ in hypothalamus and pancreas. Proc. Natl. Acad. Sci. USA 79: 917921.

Bcnoit, R., N. Ling, B. Alford, and R. Guillemin (1982b) Seven peptides derived from pro-somatostatin in rat brain. Biochem. Biophys. Res. Commun. 107: 944-950.

Bieger, D. (1984) Muscarinic activation of rhombencephalic neurones controlling oesophageal peristalsis in the rat. Neuropharmacology 23 : 1451-1464.

Bieger, D., and D. A. Hopkins (1987) Viscerotopic representation on the upper alimentary tract in the medulla oblongata in the rat: The nucleus ambiguus. J. Comp. Neurol. 262: 546-562.

Blessing, W. W., S. C. Hedger, T. H. Joh, and J. O. Willoughby (1987) Neurons in the area postrema are the only catecholamine-synthesizing cells in the medulla or pons with projections to the rostral ventrolateral medulla (C1-area) in the rabbit. Brain Res. 419: 336-340.

Ciriello, J., M. M. Caverson, and C. Polosa (1986) Function of the ventrolatcral medulla in the control of the circulation. Brain Res. Rev. 11: 359-391.

Cottle, M. K., and F. R. Calaresu (1975) Projections from the nucleus and tractus solitarius in the cat. J. Comp. Neurol. 161: 143-158.

Cunningham, E. T., Jr., and P. E. Sawchenko (1987) Projections from the $\mathrm{C} 1, \mathrm{C} 2$, and $\mathrm{C} 3$ adrenergic cell groups to the paraventricular and supraoptic nuclei of the rat hypothalamus. Anat. Rec. 214:27A.

Cunningham, E. T., Jr., and P. E. Sawchenko (1988) Anatomical specificity of noradrenergic inputs to the paraventricular and supraoptic nuclei of the rat hypothalamus. J. Comp. Neurol. 274: 60-76.

Dampney, R. A. L., J. Czachurski, K. Dembowsky, A. K. Goodchild, and $H$. Seller (1987) Afferent connections and spinal projections of the pressor region in the rostral ventrolateral medulla of the cat. J. Autonom. Nerv. Syst. 20: 73-86.

Diz, D. I., K. L. Barncs, and C. M. Ferrario (1987) Functional characteristics of neuropeptides in the dorsal medulla oblongata and vagus nerve. Fed. Proc. 46: 30-35.

Dockray, C. J., and K. A. Sharkey (1986) Neurochemistry of visceral afferent neurons. In Progress in Brain Research, Vol. 67: Visceral Sensation, F. Cervero and J. F. B. Morrison, eds., pp. 133-148, Elsevier, New York.

Doty, R. W. (1968) Neural organization of deglutition. In Handbook of Physiology. Alimentary Canal, Sec. 6, Vol. 4, C. F. Code, ed., pp. 1861-1902, Am. Physiol. Soc., Washington, D.C.

Finley, J. C. W., J. L. Maderdrut, L. J. Roger, and P. Petrusz (1981) The immunocytochemical localization of somatostatin-containing neurons in the rat central nervous system. Neuroscience 6: 21732192.

Fryscak, T., W. Zenker, and D. Kantner (1984) $\Lambda$ fferent and efferent innervation of the rat esophagus. Anat. Embryol. 170: 63-70.

Gerfen, C. R., and P. E. Sawchenko (1984) An anterograde neuroanatomical tracing method that shows the detailed morphology of neurons, their axons and terminals: Immunohistochemical localization of an anterogradely transported plant lectin, Phaseolus vulgaris-leucoagglutinin (PHA-L). Brain Res. 290: 219-238.

Gerfen, C. R., and P. E. Sawchenko (1985) A method for anterograde axonal tracing of chemically specified circuits in the central nervous system: Combined Phaseolus vulgaris-leucoagglutinin (PHA-L) tract tracing and immunohistochemistry. Brain Res. 343: 144-150.

Hopkins, D. A. (1987) The dorsal motor nucleus of the vagus nerve and the nucleus ambiguus: Structure and connections. In Cardiogenic Reflexes, R. Hainsworth, P. N. McWilliam and D. A. S. G. Mary, cds., pp. 185-203, Oxford U. P., Oxford, UK.

Houser, C. R., G. D. Crawford, R. P. Barber, P. M. Salvaterra, and J. E. Vaughn (1983) Organization and morphological characteristics of cholinergic neurons: An immunocy tochemical study with a monoclonal antibody to choline acetyltransferase. Brain Res. 266: 97-119.

Jankowska, E. (1987) Interneurons. In Encyclopedia of Neuroscience, Vol. 1, G. Adelman, ed., pp. 541-542, Birkhäuser, Boston.

Jean, A. (1972a) Localisation et activité des neurones déglutiteurs bulbaires. J. Physiol. (Paris) 64: 227-268.

Jean, A. (1972b) Effet de lésions localisées du bulbe rachidien sur le stade oesophagien de la déglutition. J. Physiol. (Paris) 64: 507-516.

Jean, A. (1978) Localisation et activité des motoneurones oesophagiens chez le mouton. J. Physiol. (Paris) 74: 737-742.
Jean, A. (1984) Control of the central swallowing program by inputs from the peripheral receptors. A review. J. Autonom. Nerv. Syst. 10: 225-233.

Iohansson, O., T. Hökfelt, and R. P. Elde (1984) Immunohistochemical distribution of somatostatin immunoreactivity in the central nervous system of the adult rat. Neuroscience 13: 265-339.

Kalia, M., and J. M. Sullivan (1982) Brain stem projections of sensory and motor components of the vagus nerve in the rat. J. Comp. Neurol. 211: $248-264$.

Kalia, M., K. Fuxe, T. Hökfelt, O. Johansson, R. Lang, D. Ganten, C. Cuello, and L. Terenius (1984) Distribution of neuropeptide immunoreactive nerve terminals within the subnuclei of the nucleus of the tractus solitarius of the rat. J. Comp. Neurol. 222: 409-444.

Kawai, Y., K. Takami, S. Shiosaka, P. C. Emson, C. J. Hillyard, S. Girgis, I. MacIntyre, and M. Tohyama (1985) Topographic localization of calcitonin gene-related peptide in the rat brain: An immunohistochemical analysis. Neuroscience 15: 747-763.

Kimura, H., P. L. McGeer, and J.-H. Peng (1984) Choline acetyltransferase-containing neurons in the rat brain. In Classical Transmitters and Transmitter Receptors in the CNS, Part II, Handbook of Chemical Neuroanatomy, Vol. 3, A. Björklund, T. Hökfelt, and M. J. Kuhar, eds., pp. 51-125, Elsevier, New York.

Kuljis, R. O., and H. J. Karten (1986) Substance P-containing cells become progressively less detectable during retinotectal dcvclopment in the frog Rana pipiens, Proc. Natl. Acad. Sci. USA 83: 5736-5740.

Lawn, A. M. (1966) The localization, in the nucleus ambiguus of the rabbit, of the cells of origin of motor nerve fibers in the glossopharyngeal nerve and various branches of the vagus nerve by means of retrograde degeneration. J. Comp. Neurol. 127: 293-306.

Leslie, R. A. (1985) Neuroactive substances in the dorsal vagal complex of the medulla oblongata: Nucleus of the tractus solitarius, area postrema, and dorsal motor nucleus of the vagus. Neurochem. Int. 7: 191-211.

Levin, M. C., P. E. Sawchenko, P. R. C. Howe, S. R. Bloom, and J. M. Polak (1987) Organization of galanin-immunoreactive inputs to the paraventricular nucleus with special reference to their relationship to catecholaminergic afferents. J. Comp. Neurol. 261: 562-582.

Loewy, A. D., and H. Burton (1978) Nuclei of the solitary tract: Efferent projections to the lower brain stem and spinal cord of the cat. J. Comp. Neurol. 181: 421-450.

Lovick, T.A. (1986) Projections from brainstem nuclei to the nucleus paragigantocellularis lateralis in the cat. J. Autonom. Nerv. Syst. 16: $1-11$.

Maley, B. E., and R. Elde (1982) Immunohistochemical localization of putative neurotransmitters within the feline nucleus tractus solitarii. Neuroscience 7: 2469-2490.

Mancillas, J. R., G. R. Siggins, and F. E. Bloom (1986) Somatostatin selectively enhances acetylcholine-induced excitations in rat hippocampus and cortex. Proc. Natl. Acad. Sci. USA 83: 7518-7521.

Meltzer, S. J. (1899) On the causes of the orderly progress of the peristaltic movements in the oesophagus. Am. J. Physiol. 2: 266272.

Meltzer, S. J. (1907) Deglutition through an oesophagus partly deprived of its muscularis, with demonstration. Proc. Soc. Exp. Biol. Med. 4: 40-43.

Miller, A. J. (1982) Deglutition. Physiol. Rev. 62: 129-184.

Miller, A. J. (1986) Neurophysiological basis of swallowing. Dysphagia 1: $91-100$.

Miller, A. J. (1987) Swallowing: Neurophysiologic control of the esophageal phase. Dysphagia 2: 72-82.

Millhorn, D. E., T. Hökfelt, L. Terenius, A. Buchan, and J. C. Brown (1987a) Somatostatin- and enkephalin-like immunoreactivities are frequently colocalized in neurons in the caudal brain stem of rat. Exp. Brain Res. 67: 420-428.

Millhorn, D. E., K. Seroogy, T. Hökfelt, L. C. Schmued, L. Terenius, A. Buchan, and J. C. Brown (1987b) Neurons of the ventral medulla oblongata that contain both somatostatin and enkephalin immunoreactivities project to nucleus tractus solitarii and spinal cord. Brain Res. 424: 99-108.

Miura, M., K. Takayama, and J. Okada (1987) Study of possible transmitters in the solitary tract nucleus of the cat involved in the carotid sinus baro- and chemoreceptor reflex. J. Autonom. Nerv. Syst. 19: $179-188$

Molhant, M. (1914) Le nerf vague. Etude anatomique et expérimentale. Deuxième partie. Le noyau ambigu; les connexions anatomique et la 
valeur fonctionelle du noyau central du vague et du noyau ambigu. Névraxe 13: 9-316.

Morest, D. K. (1967) Experimental study of the projections of the nucleus of the tractus solitarius and the area postrema in the cat. J. Comp. Neurol. 130: 277-300.

Morrison, J. H., R. Benoit, P. J. Magistretti, N. Ling, and F. E. Bloom (1982) Immunohistochemical distribution of prosomatostatin related peptides in hippocampus. Neurosci. Lett. 34: 137-142.

Morrison, J. H., R. Benoit, P. J. Magistretti, and F. E. Bloom (1983) Immunohistochemical distribution of pro-somatostatin-related peptides in cerebral cortex. Brain Res. 262: 344-351.

Morrison, S. F., T. A. Milner, and D. J. Reis (1988) Reticulospinal vasomotor neurons of the rat rostral ventrolateral medulla: Relationship to sympathetic nerve activity and the $\mathrm{Cl}$ adrenergic cell group. J. Neurosci. 8(4): 1286-1301.

Norgren, R. (1978) Projections from the nucleus of the solitary tract in the rat. Neuroscience 3: 207-218.

Norgren, R. (1984) Central neural mechanisms of taste. In The Nervous System: Sensory Processes, V. B. Mountcastle sect. ed., F. E. Bloom, vol. ed., pp. 1087-1124, American Physiological Society, Bethesda, MD.

Oomura, Y., and Y. Mizuno (1986) Effect of somatostatin on the vagal motor neuron in the rat. Brain Res. Bull. 17:397-401.

Palkovits, M. (1985) Distribution of neuroactive substances in the dorsal vagal complex of the medulla oblongata. Neurochem. Int. 7 : 213-219.

Palkovits, M., and L. Záborsky (1977) Neuroanatomy of central cardiovascular control. Nucleus tractus solitarii: Afferent and efferent neuronal connections in relation to the baroreceptor reflex arc. Prog. Brain Res. 47: 9-34

Reis, D. J. (1988) The brain and hypertension. Arch. Neurol. 45: 180182.

Ricardo, J. A., and E. T. Koh (1978) Anatomical evidence of direct projections from the nucleus of the solitary tract to the hypothalamus, amygdala, and other forebrain structures in the rat. Brain Res. 153. $1-26$.

Rodrigo, J., J. M. Polak, L. Fernandex, M. A. Ghatei, P. Mulderry, and S. R. Bloom (1985) Calcitonin gene-related peptide immunoreactive sensory and motor nerves of the rat, cat, and monkey esophagus. Gastroenterology 88: 444-451.

Rosenfeld, M. G., J.-.J. Mermod, S. G. Amara, L. W. Swanson, P. E. Sawchenko, J. Rivier, W. W. Vale, and R. M. Evans (1983) Production of a novel neuropeptide encoded by the calcitonin gene via tissue-specific RNA processing. Nature 304: 129-135.

Ross, C. A., D. M. Armstrong, D. A. Ruggiero, V. M. Pickel, T. H. Joh, and D. J. Reis (1981) Adrenaline neurons in the rostral ventrolateral medulla innervate thoracic spinal cord: A combined immunocytochemical and retrograde transport demonstration. Neurosci. Lett. 25: 257-262.
Ross, C. A., D. A. Ruggiero, T. H. Joh, D. H. Park, and D. J. Reis (1983) Adrenaline synthesizing neurons in the rostral ventrolateral medulla: A possible role in tonic vasomotor control. Brain Res. 273: 356-361.

Ross, C. A., D. A. Ruggiero, T. H. Joh, D. H. Park, and D. J. Reis (1984) Rostral ventrolateral medulla: Selective projections to the thoracic autonomic cell column from the region containing $\mathrm{Cl}$ adrenaline neurons. J. Comp. Neurol. 228: 168-185.

Ross, C. A., D. A. Ruggiero, and D. J. Reis (1985) Projections from the nucleus tractus solitarii to the rostral ventrolateral medulla. J. Comp. Neurol. 242: 511-534.

Sawchenko, P. E. (1983) Central connections of the sensory and motor nuclei of the vagus nerve. J. Autonom. Nerv. Syst. 9: 13-26.

Sawchenko, P. E., and L. W. Swanson (1982) The organization of noradrenergic pathways from the brainstem to the paraventricular and supraoptic nuclei in the rat. Brain Res. Rev. 4: 275-325.

Sawchenko, P. E., E. T. Cunningham, Jr., and M. C. Levin (1987) Anatomic and biochemical specificity in central autonomic pathways. In Organization of the Autonomic Nervous System: Central and Peripheral Mechanisms, J. Ciriello, F. R. Calaresu, L. P. Renaud, and C. Polosa, eds., pp. 267-281, Liss, New York.

Sawchenko, P. E., R. Benoit, and M. R. Brown (1988) Somatostatin 28-immunoreactive inputs to the paraventricular and supraoptic nuclei: Principal origin from non-aminergic neurons in the nucleus of the solitary tract. J. Chem. Neuroanat. 1: 81-94.

Schmued, L. C., and J. H. Fallon (1986) Fluoro-gold: A new fluorescent retrograde axonal tracer with numerous unique properties. Brain Res. 377: 147-154.

Sengupta, A., and R. K. Goyal (1988) Localization of galanin immunoreactivity in the opossum esophagus. J. Autonom. Nerv. Syst. 22: 49-56.

Siggins, G. R., and D. L. Gruol (1986) Mechanisms of transmitter action in the vertebrate central nervous system. In The Nervous System: Intrinsic Regulatory Systems of the Brain, V. B. Mountcastle, sect. ed., F. E. Bloom, vol. ed., pp. 1-114, American Physiological Society, Bethesda, MD.

Stuesse, S. L., and S. E. Fish (1984) Projections to the cardioinhibitory region of the nucleus ambiguus of rat. J. Comp. Neurol. 229: 271278.

Sumi, T. (1964) Neuronal mechanisms in swallowing. Pfluegers Arch. 278: $467-477$.

Talman, W. T., A. R. Granata, and D. J. Reis (1984) Glutamatergic mechanisms in the nucleus tractus solitarius in blood pressure control. Fed. Proc. 43: 39-44.

Yamazoe, M., S. Shiosaka, T. Shibasaki, N. Ling, K. Tateishi, E. Hashimura, T. Hamaoka, J. R. Kimmel, H. Matsuo, and M. Tohyama (1984) Distribution of six neuropeptides in the nucleus tractus solitarii of the rat: An immunohistochemical analysis. Neuroscience 3: 1243-1266. 